\title{
Fluid management for children presenting to the emergency department: Guidelines for clinical practice
}

\author{
Dianne Crellin, RN, NP, BN, Cert (Emerg), GradDip (Paed), MN ${ }^{a, b, *}$
}

\author{
a Emergency Department, Royal Children's Hospital, Melbourne, Australia \\ b School of Nursing, The University of Melbourne, Australia
}

Received 22 November 2007; received in revised form 2 December 2007; accepted 3 December 2007

\section{KEYWORDS \\ Pediatric fluid \\ management; \\ Unwell child; \\ Dehydration; \\ Hypovolaemia}

\begin{abstract}
Summary Acute illness in children is frequently accompanied by fluid balance disturbances with many children experiencing hypovolaemia and/or dehydration of varying severity. Much of the evidence supporting fluid choice and management regimens stems from studies conducted on adults and well children. However, it is clear from more recent work concentrating on infants and children that physiological immaturity and the effects of acute illness impact significantly on their fluid requirements and responses to treatment. Guidelines exist for fluid resuscitation, fluid replacement and maintenance therapy, which are suitable in most circumstances for infants and children presenting to the ED with hypovolaemia and dehydration secondary to acute illness.

Small numbers of children presenting to the ED will have unique fluid requirements (e.g. children with cardiac disease, DKA, etc.) and these circumstances along with blood loss and other trauma-related fluid management issues (e.g. burns) is outside the scope of this paper and will not be discussed.
\end{abstract}

(c) 2007 College of Emergency Nursing Australasia Ltd. Published by Elsevier Ltd. All rights reserved.
Acute illness in children is frequently accompanied by fluid balance disturbances with many children experiencing hypovolaemia and/or dehydration of varying severity. Much of the evidence supporting fluid choice and management regimens stems from studies conducted on adults and well children. However, it is clear from more recent work concentrating on infants and children that physiological immaturity and the effects of acute illness impact

\footnotetext{
* Tel.: +6139345 5331

E-mail address: dianne.crellin@rch.org.au.
}

significantly on their fluid requirements and responses to treatment. Guidelines exist for fluid resuscitation, fluid replacement and maintenance therapy, which are suitable in most circumstances for infants and children presenting to the ED with hypovolaemia and dehydration secondary to acute illness.

Small numbers of children presenting to the ED will have unique fluid requirements (e.g. children with cardiac disease, DKA, etc.) and these circumstances along with blood loss and other trauma-related fluid management issues (e.g. burns) is outside the scope of this paper and will not be discussed. 


\section{Physiology}

Accurately assessing and appropriately managing paediatric fluid balance is contingent on having a good understanding of the physiology controlling fluid balance, the physiological impact of immaturity and the effects of acute illness on fluid balance.

\section{Cardiovascular}

The physical immaturity and smaller size of the infant compared to the adult result in significant structural and functional differences in the cardiovascular system and the maintenance of fluid balance. These differences impact on the response to hypovolaemia and dehydration of the infant and child and in turn this effects clinical assessment, the interpretation of findings and the strategies used to restore the circulation and manage fluid balance. ${ }^{1,2}$

Organ perfusion is dependent on a number of factors including cardiac output, which is a function of heart rate and stroke volume. Adult heart rate and stroke volume are variable and tightly controlled to ensure adequate perfusion. However, fewer actomyosin elements and mitochondria render the infant myocardium unable to increase contractility resulting in a relatively fixed stroke volume. For this reason, infants have a greater reliance on increases in heart rate to increase cardiac output when compared to the adult. ${ }^{1,2}$

Release of calcium from the sarcoplasmic reticulum in the infant myocardium is less efficient than from adult myocardium making infant contractility more dependent on extracellular calcium concentrations, which has implications for fluid administration and electrolyte monitoring. ${ }^{2,3}$

Infant myocardial compliance is also lower than the adults and so for the same ventricular filling volume infants will experience higher atrial pressures. This has a negative effect on preload and also restricts capacity to increase stroke volume. ${ }^{2}$ This helps explain the infants relatively poor response to aggressive fluid resuscitation which aims to augment cardiac output. ${ }^{1}$

Despite this the cardiac index is at its highest in infancy ( $300 \mathrm{ml} /(\mathrm{min} \mathrm{kg})$ compared to $70-80 \mathrm{ml} /(\mathrm{min} \mathrm{kg})$ in adults), which is a reflection of a much higher resting heart rate. ${ }^{1}$ This serves to meet the substantially higher metabolic requirements of the infant.

Blood pressure increases with age and is predominantly a result of a corresponding increase in systemic vascular resistance. ${ }^{1}$ Assessment of blood pressure will be discussed more extensively in one of the following sections.

\section{Fluid and electrolytes}

The distribution of body water across fluid compartments also varies with age. However, after approximately 6 months of age total body water remains constant at around $60-65 \mathrm{ml} / \mathrm{kg}$ having fallen from $80 \mathrm{ml} / \mathrm{kg}$ at birth and the distribution between intracellular and extracellular fluid resembles the adult. ${ }^{2}$ The difference in total body fluid and distribution are partly responsible for the infants increased susceptibility to dehydration. Additionally, infant circulating blood volume is higher than the circulat- ing blood volume of an adult $(70-80 \mathrm{ml} / \mathrm{kg}$ compared to $60-70 \mathrm{ml} / \mathrm{kg})$. $^{1}$

The glomerular filtration rate (GFR) and renal blood flow of the infant are lower than the adults GFR and the infant kidney has less capacity to concentrate the urine and excrete a solute load than the adult kidney. Renal immaturity limits the capacity of the kidneys to respond aggressively to hypovolaemia, low cardiac output and dehydration. ${ }^{2}$ In addition, the infant is less able to acidify the urine and is more sensitive to hyperchloraemic acidosis resulting from large volume resuscitation with normal saline. ${ }^{2,3}$

\section{Effect of acute illness}

Acute illness provokes an increase in cardiac output to supply oxygen and glucose to the tissues and remove waste products. Shock occurs when perfusion is insufficient to meet the metabolic needs of cells. ${ }^{1}$ Infants rely heavily on heart rate to increase their cardiac output and rates as high as 220 beats/min are seen in hypovolaemic infants. ${ }^{1}$ This compensatory mechanism is easily exhausted making infants more vulnerable to shock. However, infants are still able to maintain their blood pressure within acceptable limits until significant intravascular volume loss has occurred, which is estimated to be as much as $30 \mathrm{ml} / \mathrm{kg}^{2}$

Infants and young children show higher tolerance to the extremes of tachycardia and hypotension as a result of higher organ oxygen supply than older adults who are suffering the effects of age on vital organ function and vasculature. This tolerance is enhanced by a higher capacity for anaerobic metabolism in infant myocardial and neural tissue than in similar tissues of the adult. ${ }^{2}$

Once stressed by the physiological derangement resulting from shock, infants demonstrate a bradycardic response in contrast to the tachycardic response of older children and adults. This is the result of the presence of fewer beta receptors in infant myocardium than adult myocardium. ${ }^{2}$

The syndrome of inappropriate antidiuretic hormone secretion (SIADH) is associated with many acute illnesses (meningitis, pneumonia, bronchiolitis, etc.). Elevated ADH levels result in conservation of water and high sodium excretion causing hyponatraemia and water overload. In a 1992 study, children with fever secondary to infection had higher ADH levels than well children. ${ }^{4}$ In more recent work, even children suffering from gastroenteritis experience an increase in $\mathrm{ADH}$ secretion with resulting normal and low serum sodium levels. ${ }^{5}$ Furthermore, hyponatraemia has been demonstrated in children suffering a range of infections such as meningitis, pneumonia, sepsis, malaria and bronchiolitis. ${ }^{6-11}$ Although Hazell et al. suggest that SIADH is over diagnosed, no compelling evidence is available to support this and SIADH should be considered when prescribing fluid management regimens for acutely unwell children.

\section{Assessment}

Hypovolaemia is evidenced by signs of poor end organ perfusion and compensatory effort ${ }^{2}$ and efforts to determine the most sensitive and specific clinical indicators of hypovolaemia have been made. The sensitivity of indicators of dehydration severity has also been evaluated extensively 
Table 1 Heart rate and blood pressure values by age

\begin{tabular}{lllc}
\hline Age & Heart rate (beats/min) & Respiratory rate (breaths/min) & Blood pressure (systolic) \\
\hline Neonate & $120-180$ & $40-60$ & $60-80$ \\
Infant (1 month to 1 year) & $110-160$ & $30-40$ & $70-90$ \\
Toddler (1-2 years) & $100-150$ & $25-35$ & $80-95$ \\
Young child (2-7 years) & $95-140$ & $25-30$ & $90-110$ \\
Older child (7-12 years) & $80-120$ & $20-25$ & $100-120$ \\
\hline
\end{tabular}

Source: Advanced Life Support Group (2005). ${ }^{1}$

and there is some overlap between these signs and those of hypovolaemia.

Evidence of compensation for fluid loss and increasing hypovolaemia are early and common signs of fluid deficit in children with acute illness. Increasing heart rate and signs of vasoconstriction such as skin pallor and mottling are two obvious indications that compensatory mechanisms have been launched to improve cardiac output and secure adequate end organ perfusion. As hypovolaemia and fluid losses increase and children deteriorate other mechanisms are employed to address the derangements resulting from hypoperfusion, e.g., tachyponea to reduce acidosis. Table 1 shows the accepted norms for heart rate and respiratory rate by age.

Decreased or altered conscious state, prolonged capillary refill, decreased urine output, increasing respiratory rate in the absence of increasing effort, and finally increasing metabolic acidosis and deteriorating blood pressure are all signs of inadequate end organ perfusion pressure and incur in children with significant hypovolaemia.

The minimum permissible urine output for infants $(2 \mathrm{ml} /(\mathrm{kgh}))$ and children $(1 \mathrm{ml} /(\mathrm{kgh}))$ is much higher than the minimum volume accepted for adults $(1 / 2 \mathrm{ml} /(\mathrm{kg} \mathrm{h}))^{1,3}$ Direct measurement of urine output in infants and children not yet toilet trained is challenging and often indirect measures like nappy weights are used as a proxy. Estimates of nappy weights are notoriously inaccurate and if this technique is used to estimate urine output the nappy should be weighed. ${ }^{12}$

\section{Accuracy of assessment parameters}

Recognition of these signs and correctly identifying them as evidence of hypovolaemia is essential as a drop in blood pressure is unlikely to be evident until approximately $30 \%$ of circulating volume is lost. ${ }^{2,3}$

The utility of clinical signs for the detection of hypovolaemia is dependent on their ability to detect hypovolaemia early and whether these signs are similarly recognized and interpreted by clinicians. There is some evidence to indicate that assessment of indirect measures of shock such as capillary refill time, pulse strength and tissue turgor is at best only moderately reliable. ${ }^{13}$

\section{Capillary refill}

Assessment of capillary refill time is recommended as a noninvasive measure of peripheral perfusion and an indirect indicator of circulating intravascular volume. ${ }^{1}$ Clinicians are cautioned about relying exclusively on this parameter, as the evidence for its sensitivity for shock in young children is not convincing. Leonard and Beattie's study demonstrated no correlation between prolonged capillary refill time (greater than $3 \mathrm{~s}$ ) and bacterial infection. ${ }^{14}$ These findings are consistent with findings from a study comparing capillary refill time with invasive cardiovascular indices, which showed poor correlation between the two. ${ }^{15}$

Studies focusing on the value of capillary refill time for estimating severity of dehydration have had greater success and indicate that it is likely to be a valuable assessment tool. ${ }^{16,17}$ Gorelick et al. has shown that capillary refill time is not affected by the presence of fever. ${ }^{18}$ Other studies indicate that sensitivity and specificity are likely to be effected by ambient temperature and the technique and site of measuring CRT. ${ }^{15,16,19-21}$

However, in the absence of more suitable parameters, capillary refill time assessment remains a means to assessing peripheral perfusion and to some extent provides an estimate of fluid balance for children presenting to the ED and two seconds is the accepted upper limit of normal.

\section{Blood pressure}

As was described earlier a drop in BP is a sign of substantial intravascular volume loss. The majority of children with acute illness do not reach this stage and our aim is for early recognition of hypovolaemia before hypotension occurs.

Hypotension is defined as a systolic blood pressure (SBP) lower than the 5 th percentile for age and Table 1 provides accepted values for different age groups. ${ }^{1,22,23}$ Variation in published values exists and this is likely to be a result of the lack of evidence supporting these recommendations. Using blood pressure measurements in well children to calculate the 5th percentile, Haque and Zaritsky make one of the first and only attempts to substantiate the values used to define hypotension. ${ }^{22}$ The results of their work indicate that most published recommendations for the lowest acceptable systolic blood pressure are actually higher than the 5 th percentile for well children. Additionally, they reveal that height also impacts significantly on blood pressure, which has not been previously recognized. The authors developed a simple formula from their data to assist the clinician to calculate systolic blood pressure for children of different ages $(1-17$ years):

$\mathrm{SBP}=2 \times$ age in years +65 
Despite this study producing SBP values founded on the best evidence base to date, the authors conclude that adoption of a higher threshold for minimum acceptable blood pressure for unwell children is a clinically rationale approach. Like capillary refill time, blood pressure monitoring is a valuable assessment tool but treatment decisions should not rest solely on this parameter, particularly where blood pressure measurement is considered normal.

Blood pressure measurements are performed less frequently on children than adults presenting to the emergency department. This is likely to reflect the practical difficulties measuring the BP in young children and infants and concerns about the accuracy of the measurement. Young children are rarely cooperative and variation in their size effects cuff selection which along with the level of anxiety, the position of the arm in relation to the heart and the type of manometer will affect the result. ${ }^{24}$ Clark et al. studied the effect of two methods for estimating the appropriate cuff size for children aged 5 days to 22 years and found deficiencies in all methods studied. ${ }^{25}$ A cuff most closely representing $40 \%$ of the circumference of the upper arm gives a measurement closest to invasive radial blood pressure values.

\section{Laboratory values}

Base deficit is considered a measure of the adequacy of cardiac output and tissue oxygenation. Given the urgency of resuscitation of the circulation and the potential delay accessing laboratory results, it has no role in guiding immediate fluid resuscitation of hypovolaemic children. Base deficit is better used as an indicator of the success of earlier treatment and a guide to ongoing resuscitation. Bicarbonate has been repeatedly shown to be the most sensitive measure of the severity of dehydration ${ }^{17,26-29}$ while other parameter such as specific gravity of urine, the presence of ketones and the urine output during rehydration are not good indicators of the severity of dehydration. ${ }^{26,30}$ However, the evidence supporting laboratory tests is not sufficiently compelling and recommendations for assessment of dehydration severity rarely include routine laboratory testing.

\section{Dehydration assessment tools}

Dehydration is best detected and quantified by changes in total body weight. ${ }^{3}$ However, accurate recent weights are often not available for young children presenting to the emergency department and clinicians must rely on assessment of the clinical features of dehydration to determine the severity. Study authors repeatedly conclude from results that clinicians poorly estimate dehydrations severity, with one Australian study revealing overestimation by as much as 3.2\%. ${ }^{17,29}$ This provides persuasive support for serial weight measurements for children presenting to the ED with the potential for fluid loss.

There is considerable overlap between the signs considered likely to indicate dehydration and those indicating hypovolaemia. Furthermore, hypovolaemia is associated with severe dehydration resulting in these children exhibiting the signs of hypovolaemic shock. Significant attention has been placed on identifying clinical signs, which are sensitive and specific for dehydration and its severity.
A history of fluid loss (diarrhea and vomiting), low urine output and poor fluid intake are considered indicative of the likely presence of dehydration. However, a meta-analysis summarizing data from three studies show that these symptoms have low predictive value for $5 \%$ dehydration. ${ }^{17,31-33}$ of greater value to hydration assessment is parental report of normal urine output, which positively predictive for normal hydration. ${ }^{33}$

Three signs are shown to have positive predictive value for detecting dehydration and they are prolonged capillary refill time, abnormal skin turgor and abnormal respiratory pattern. ${ }^{16,17,26,33,34}$ Otieno et al. ${ }^{13}$ report that skin turgor is the single most reliable sign of dehydration in children. Signs such as the absence of tears, cool extremities, sunken eyes, dry mucus membranes, ill appearance and a weak pulse may be of some clinical value to the assessment of hydration but results are variable and demonstrate weaker predictive value.

Given the variability in study results, the rational approach for clinicians is to approximate severity of dehydration based on the number of signs of dehydration identified rather than the presence of specific individual signs. Several authors have published results demonstrating that dehydration assessment tools comprised of several signs have greater predictive value than individual signs. ${ }^{33,34}$ Friedman et al. identified the combination of general appearance, eyes (sunken), mucous membranes, and tears as likely to give the most sensitive indication of dehydration severity. ${ }^{35}$ Table 4 provides details for the Gorelick et al. [18] model for estimating dehydration severity.

\section{Management}

The aim of fluid management is to treat hypovolaemia, replace fluid deficits, and provide for ongoing losses and maintenance fluid requirements. Fluid type, the volume and the method of administration are some of the decisions to be made when prescribing and managing fluids for children in the ED.

\section{Hypovolaemia}

Hypotension has been repeatedly demonstrated to be associated with higher rates of mortality ${ }^{36,37}$ and aggressive early normalization of blood pressure values improves survival. ${ }^{1-3,38}$ Only small numbers of children present with hypotension while much larger numbers reveal signs of hypovolaemia requiring fluid resuscitation.

The aim of treatment is to increase circulating blood volume and fluids are selected based on their capacity to achieve this. Hypotonic fluids do not remain in the intravascular space and are therefore not suitable for resuscitation. Colloids were considered likely to remain in the circulation for longer than isotonic crystalloids and for many years they were the mainstay of fluid resuscitation.

Initially, albumin was viewed as the ideal colloid; however early study results prompted concern that resuscitation with albumin increased mortality. Recommendations were qualified to advocate for albumin as a more appropriate volume expander in specific circumstances, e.g., sepsis and while less appropriate in others, e.g., head trauma. ${ }^{39,40}$ 
(A)

(B)

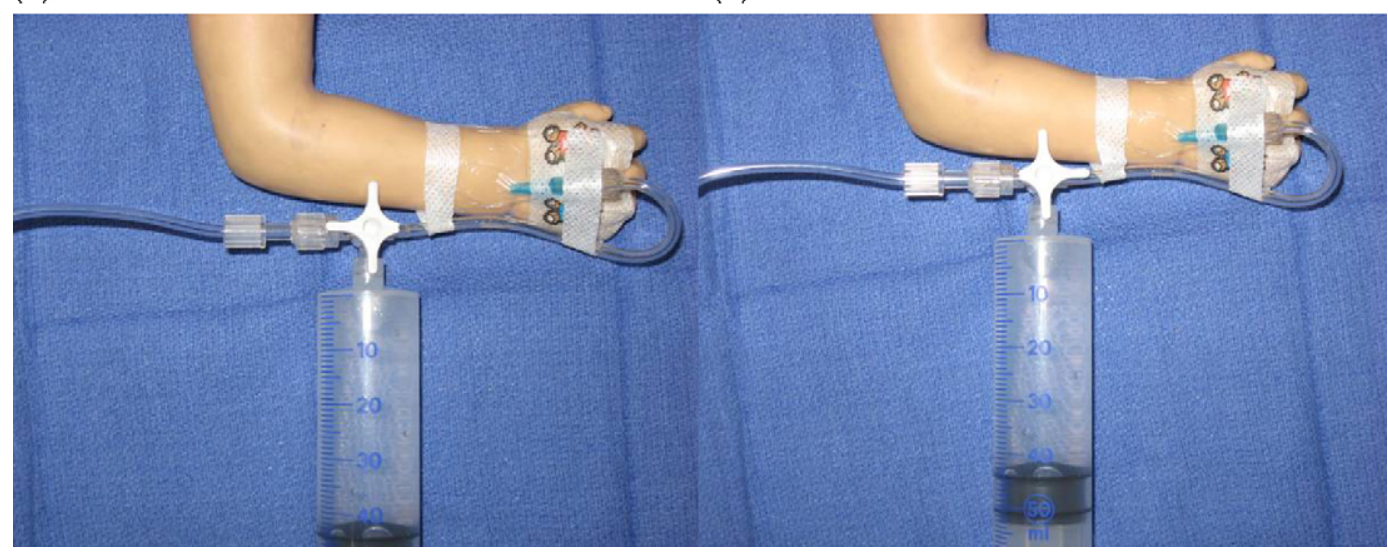

Figure 1 Line set up to administer bolus of fluid via an intraosseous cannula or a small gauge IV cannula: (A) withdrawing fluid from fluid bag into syringe; (B) injecting fluid into the patient.

The results of the recently updated Cochrane review show that isotonic crystalloids and colloids are equally suited to restore circulating blood volume despite the theoretical advantage attributed to colloids and that an increase in adverse events is not associated with specific fluids. ${ }^{41}$ Crystalloid fluids are widely available and inexpensive making them the fluid type of choice. ${ }^{39,41}$ Normal saline has been the most commonly recommended crystalloid for fluid resuscitation. However, overuse carries some risk in the form of hyperchloraemic acidosis. More recently Hartmann's solution is gaining favour as this solution unlike normal saline contains lactate which when converted to bicarbonate acts as a buffer. ${ }^{3}$

Volume recommendations for treatment of hypovolaemia most frequently support $20 \mathrm{ml} / \mathrm{kg}$ boluses of fluid. ${ }^{1-3}$ This choice is largely arbitrary and founded on a study which suggests that signs of hypovolaemic shock are exhibited with loss of approximately $30 \%$ of circulating volume, which equates to approximately $20 \mathrm{ml} / \mathrm{kg}^{3}$ Fluid will only remain in circulation for a relatively short time and repeat bolus of fluid are likely to be required particularly where there is a total body fluid deficit or large volume shifts as in sepsis. Aggressive fluid administration of up to $80-100 \mathrm{ml} / \mathrm{kg}$ over an hour may be required to achieve adequate perfusion in children with sepsis.

Direct intravenous access is the most common route of administration of fluids, however in children with profound hypovolaemia and poor peripheral perfusion gaining access can be extremely difficult. Intraosseous access (IO) is the alternative and clinicians should have a low threshold (one to two brief attempts to cite an intravenous (IV) cannula) for using this route for administration of fluids to the shocked child. ${ }^{3}$ Intraosseous insertion is much easier than IV insertion and increasingly this is made even easier with the availability of devices such as bone drills and bone guns.

Fluids given via an 10 will not run on a gravity drip set and must be pumped under pressure. This can be achieved using manual blood pump sets, syringes and pressure bags. Rapid delivery of fluids via small IV cannulae will also require higher pressure. For smaller volumes fluid boluses can be given by 'pushing' fluids with a 20 or $50 \mathrm{ml}$ syringe connected to a three-way tap in the fluid line (see Fig. 1). Administration of larger volumes will require use of infusion pumps, pressure bags or blood pump sets.

\section{Dehydration}

Intravenous replacement of fluid is not considered the ideal method of fluid administration for dehydration in the absence of associated hypovolaemia. Evidence from a meta-analysis and a systematic review demonstrate that oral replacement of the fluid deficit is achieved at least as effectively as intravenous replacement of the deficit ${ }^{42,43}$

Table 2 Composition of a commercial ORS and commonly available drinks

\begin{tabular}{lcccc}
\hline Solution & $\mathrm{Na}(\mathrm{mmol} / \mathrm{l})$ & $\mathrm{K}(\mathrm{mmol} / \mathrm{l})$ & Carbohydrate $(\mathrm{mmol} / \mathrm{l})$ & Osmolarity $(\mathrm{mmol} / \mathrm{kg})$ \\
\hline WHO recommendation & 90 & 20 & 111 & 310 \\
Reduced osmolarity solution & 75 & 20 & 75 & 245 \\
Hydrolyte & 55 & 20 & 80 & 230 \\
Soft drink & 2 & 0 & 700 & 750 \\
Apple juice & 3 & 32 & 690 & 730 \\
Broth & 250 & 8 & 0 & 500 \\
Sports drink & 20 & 3 & 255 & 340 \\
Tea & 0 & 0 & 0 & 5 \\
\hline
\end{tabular}

Note: WHO, World Health Organisation. Source: Hahn, Kim, and Garner (2002) and Gastanaduy and Begue (1999). ${ }^{44,45}$ 
Table 3 Recommended hourly rate for oral or nasogastric rehydration

\begin{tabular}{|c|c|c|c|c|}
\hline \multirow[t]{3}{*}{ Weight on admission (kg) } & \multicolumn{4}{|c|}{ Degree of dehydration } \\
\hline & \multicolumn{2}{|c|}{ Moderate (4-6\%) } & \multicolumn{2}{|l|}{ Severe (>7\%) } \\
\hline & $\mathrm{ml} / \mathrm{h} 0-6 \mathrm{~h}$ & $\mathrm{ml} / \mathrm{h} 7-24 \mathrm{~h}$ & $\mathrm{ml} / \mathrm{h} 0-6 \mathrm{~h}$ & $\mathrm{ml} / \mathrm{h} 7-24 \mathrm{~h}$ \\
\hline 3.0 & 25 & 20 & 45 & 20 \\
\hline 4.0 & 35 & 30 & 60 & 30 \\
\hline 5.0 & 45 & 35 & 75 & 35 \\
\hline 6.0 & 55 & 40 & 90 & 40 \\
\hline 7.0 & 60 & 45 & 100 & 45 \\
\hline 8.0 & 70 & 50 & 115 & 50 \\
\hline 9.0 & 80 & 55 & 130 & 55 \\
\hline 10 & 90 & 60 & 150 & 60 \\
\hline 12 & 105 & 65 & 175 & 65 \\
\hline 15 & 135 & 70 & 220 & 70 \\
\hline 20 & 175 & 85 & 290 & 85 \\
\hline 30 & 260 & 90 & 440 & 90 \\
\hline
\end{tabular}

Source: Royal Children's Hospital (Melbourne) (2004). ${ }^{46}$

Table 4 Assessment tool to determine dehydration severity

Signs of dehydration

Decreased skin elasticity

Capillary refill $>2 \mathrm{~s}$

General appearance (ill)

Absence of tears

Abnormal respirations

Dry mucus membranes

Sunken eyes

Abnormal radial pulse

Tachycardia $(H R>150)$

Decreased urine output

Fewer than three signs = mild dehydration = three to six signs: moderate dehydration; greater than six signs=severe dehydration. Source: Gorelick, Shaw, and Murphy (1997). ${ }^{33}$

and may be safer than intravenous rehydration. ${ }^{43}$ Oral fluid replacement largely avoids the potential fluid, electrolyte and acid-base imbalances that can occur with intravenous fluid management.

Oral rehydration can be safely and effectively achieved using oral rehydration solutions (ORS) based on the recommendations of the World Health Organisation (Table 2). In children admitted to hospital with diarrhoea, reduced osmolarity ORS when compared to WHO standard ORS is asso- ciated with fewer unscheduled intravenous fluid infusions, lower stool volume post-randomization, and less vomiting. No additional risk of developing hyponatraemia when compared with WHO standard ORS was detected. ${ }^{44}$ This is now the standard composition of ORS used in developed countries. Table 3 summarises the composition of a commercial oral rehydration solution (ORS) and a number of commonly available fluids. ${ }^{45}$ Fruit juices and soft drinks require considerable dilution (one part to four parts water) if they are to be used as an alternative to ORS for children refusing to drink ORS. ${ }^{46}$

It is recommended that oral fluid replacement for children with moderate to severe dehydration is given over $6 \mathrm{~h}$ to prevent fluid and electrolyte imbalances and Table 4 documents the volume of fluid administered by weight for children with moderate and severe dehydration. ${ }^{46}$ However, when electrolyte imbalance is not a concern, rapid rehydration regimens advocating $25 \mathrm{ml} /(\mathrm{kgh})$ to replace fluid losses over $3-4 \mathrm{~h}$ are increasingly used for rehydration.

A small study compared children's tolerance of frozen ORS and ORS given as a fluid provides evidence for the increasing use of ORS icy poles in ED and at home. ${ }^{47}$ Children in the study were more likely to tolerate frozen ORS than conventional ORS. Children with only mild dehydration can usually be encouraged to drink sufficient amounts of fluid to maintain adequate hydration. Those children with dehydration who refuse to drink, are not tolerating oral fluids or are exhibiting signs of moderate to severe dehydration can

Table 5 Water calculation for healthy children per day and per hour

\begin{tabular}{llll}
\hline & \multicolumn{2}{l}{ Body weight } & \\
\cline { 2 - 3 } & $<10 \mathrm{~kg}$ & $10-20 \mathrm{~kg}$ & $>20 \mathrm{~kg}$ \\
\hline Daily & $100 \mathrm{ml} / \mathrm{kg}$ & $1000 \mathrm{ml}+50 \mathrm{ml} / \mathrm{kg}$ for each $\mathrm{kg}>10 \mathrm{~kg}$ & $1500 \mathrm{ml}+20 \mathrm{ml} / \mathrm{kg} \mathrm{for} \mathrm{each} \mathrm{kg}>20 \mathrm{~kg}$ \\
Hourly & $4 \mathrm{ml} /(\mathrm{kgh})$ & $40 \mathrm{ml} / \mathrm{h}+2 \mathrm{ml} / \mathrm{kg}$ for each $\mathrm{kg}>10 \mathrm{~kg}$ & $60 \mathrm{ml}+1 \mathrm{ml} / \mathrm{kg} \mathrm{for} \mathrm{each} \mathrm{kg}>20 \mathrm{~kg}$ \\
\hline
\end{tabular}

Source: Henning (1995) and Hazell and Wilkins (2006). ${ }^{2,3}$ 
in most circumstances be successfully rehydrated enterally via a nasogastric (NG) tube.

Nasogastric tube insertion can be safely and quickly achieved in the ED to provide for fluid replacement. ${ }^{2,3}$ Children requiring nasogastric rehydration are usually in the infant and toddler age group and are therefore not cooperative. This means restraining children during insertion and using strategies to prevent them pulling the tube out and means to alleviate their distress. The use of local anaesthetic agents does not appear frequently in practice recommendations. However, it is accepted that NG tube insertion is one of the most painful procedures performed in ED. ${ }^{48,49}$ Fine bore tubes (eg: french guage 8 ) and continuous administration of fluid by feeding pump or manual drip set will be best tolerated.

\section{Maintenance fluid management}

The purpose of maintenance fluids is to provide sufficient water and electrolyte to allow for normal urine output at a similar osmolality to extracellular fluid, where oral intake is insufficient to meet requirements. Children with acute illness often drink poorly and have higher losses (insensible, vomiting and diarrhea). A common water calculation for maintenance fluids for healthy children is provided in Table 5. 2,3,39 However, calculations were based on data collected from healthy children. As explained earlier, acute illness is often associated with an increase in ADH secretion resulting in water retention and varying levels of hyponatraemia. Therefore, maintenance fluid regimens based on the needs of healthy children are considered unsuitable for acutely unwell children. Less water should be prescribed to children suffering illness where water retention is possible or a positive water balance would be harmful, e.g., brain injury and severe respiratory disease. Hypotonic solutions are no longer recommended and maintenance volumes should be reduced by one third. ${ }^{2,3,39}$ The accepted view is that isotonic solutions such as normal saline are more appropriate than hypotonic solutions and are now advocated for maintenance fluid therapy. $2,3,39,50,51$

\section{Summary}

Hypovolaemia and dehydration of varying levels of severity are common complications associated with acute illness in children and infants. Assessment and management of fluid balance is a feature of the care provided to large numbers of children presenting to the emergency department (ED). Recognition of intravascular volume deficit and dehydration and prescription of an appropriate fluid in appropriate volumes using the most suitable method of administration constitute some of the challenges for ED clinicians. However, there are recommendations available to guide treatment decisions, which are supported by a growing evidence base.

\section{Competing interests}

None declared.

\section{Funding}

None declared.

\section{References}

1. Advanced Life Support Group. Advanced paediatric life support: the practical approach. 4th ed. London: Blackwell Publishing; 2005.

[2]. Henning R. Fluid resuscitation in children. Emergency medicine. In: Proceedings of the second symposium on fluid replacement. 1995. p. 57-62.

3. Hazell W, Wilkins B. Disorders of fluids, electrolytes and acid-base. In: Cameron P, Jelinek G, Everitt I, Browne G, Raftos J, editors. Textbook of paediatric emergency medicine. Edinburgh: Churchill Livingstone; 2006.

4. Sharples PM, Seckl JR, Human D, Lightman SL, Dunger DB. Plasma and cerebrospinal fluid arginine vasopressin in patients with and without fever. Arch Dis Child 1992 August;67(8):998-1002.

5. Neville KA, Verge CF, O'Meara MW, Walker JL. High antidiuretic hormone levels and hyponatremia in children with gastroenteritis. Pediatrics 2005 December;116(6):1401-7.

6. Poddar U, Singhi S, Ganguli NK, Sialy R. Water electrolyte homeostasis in acute bronchiolitis. Indian Pediatr 1995 January;32(1):59-65.

7. Kanakriyeh M, Carvajal HF, Vallone AM. Initial fluid therapy for children with meningitis with consideration of the syndrome of inappropriate anti-diuretic hormone. Clin Pediatr 1987 March;26(3):126-30.

8. von Vigier RO, Colombo SM, Stoffel PB, Meregalli P, Truttmann AC, Bianchetti MG. Circulating sodium in acute meningitis. Am J Nephrol 2001 March-April;21(2):87-90.

9. Dhawan A, Narang A, Singhi S. Hyponatraemia and the inappropriate $\mathrm{ADH}$ syndrome in pneumonia. Ann Trop Paediatr 1992;12(4):455-62.

10. McJunkin JE, de los Reyes EC, Irazuzta JE, Caceres MJ, Khan RR, Minnich LL, et al. La Crosse encephalitis in children. N Engl J Med 2001 March;344(11):801-7.

11. Jensen AG, Wachmann CH, Poulsen KB, Espersen F, Scheibel $J$, Skinhoj P, et al. Risk factors for hospital-acquired Staphylococcus aureus bacteremia. Arch Intern Med 1999 July;159(13):1437-44.

12. Ledbetter L. Can they or can they not? Nurses' ability to quantify stool in superabsorbent diapers. J Pediatr Nurs 2006 August;21(4):325-8.

13. Otieno H, Were E, Ahmed I, Charo E, Brent A, Maitland K. Are bedside features of shock reproducible between different observers? Arch Dis Child 2004 October;89(10):977-9.

14. Leonard PA, Beattie TF. Is measurement of capillary refill time useful as part of the initial assessment of children? Eur J Emerg Med 2004 June; 11(3):158-63.

15. Tibby SM, Hatherill M, Murdoch IA. Capillary refill and coreperipheral temperature gap as indicators of haemodynamic status in paediatric intensive care patients. Arch Dis Child 1999 February;80(2):163-6.

16. Saavedra JM, Harris GD, Li S, Finberg L. Capillary refilling (skin turgor) in the assessment of dehydration. Am J Dis Child 1991 March;145(3):296-8.

17. Mackenzie A, Barnes G, Shann F. Clinical signs of dehydration in children. Lancet 1989;2(8663):605-7.

18. Gorelick MH, Shaw KN, Murphy KO, Baker MD. Effect of fever on capillary refill time. Pediatr Emerg Care 1997;13(5):305-7.

19. Gorelick MH, Shaw KN, Baker MD. Effect of ambient temperature on capillary refill in healthy children. Pediatrics 1993;92(5):699-702. 
20. Martin H, Norman M. Skin microcirculation before and after local warming in infants delivered vaginally or by caesarean section. Acta Paediatr 1997 March;86(3):261-7.

21. Raju NV, Maisels MJ, Kring E, Schwarz-Warner L. Capillary refill time in the hands and feet of normal newborn infants. Clin Pediatr 1999 March;38(3):139-44.

22. Haque IU, Zaritsky AL. Analysis of the evidence for the lower limit of systolic and mean arterial pressure in children. Pediatr Crit Care Med 2007 March;8(2):138-44.

23. Goldstein B, Giroir B, Randolph A, International pediatric sepsis consensus conference: definitions for sepsis and organ dysfunction in pediatrics. Pediatr Crit Care Med 2005 January;6(1): 2-8.

24. Bailey $\mathrm{RH}$, Bauer JH. A review of common errors in the indirect measurement of blood pressure. Sphygmomanometry. Arch Intern Med 1993 December;153(24):2741-8.

25. Clark JA, Lieh-Lai MW, Sarnaik A, Mattoo TK. Discrepancies between direct and indirect blood pressure measurements using various recommendations for arm cuff selection. Pediatrics 2002 November;110(5):920-3.

26. English M, Waruiru C, Mwakesi R, Marsh K. Signs of dehydration in severe childhood malaria. Trop Doctor 1997 October;27(4):235-6.

27. Teach SJ, Yates EW, Feld LG. Laboratory predictors of fluid deficit in acutely dehydrated children. Clin Pediatr 1997 July;36(7):395-400.

28. Yilmaz K, Karabocuoglu M, Citak A, Uzel N. Evaluation of laboratory tests in dehydrated children with acute gastroenteritis. J Paediatr Child Health 2002 June;38(3):226-8.

29. Vega RM, Avner JR. A prospective study of the usefulness of clinical and laboratory parameters for predicting percentage of dehydration in children. Pediatr Emerg Care 1997 June;13(3):179-82.

30. Steiner MJ, Nager AL, Wang VJ. Urine specific gravity and other urinary indices: inaccurate tests for dehydration. Pediatr Emerg Care 2007 May;23(5):298-303.

31. Steiner MJ, DeWalt DA, Byerley JS. Is this child dehydrated? JAMA 2004 June 9;291(22):2746-54.

32. Porter SC, Fleisher GR, Kohane IS, Mandl KD. The value of parental report for diagnosis and management of dehydration in the emergency department. Ann Emerg Med 2003 February;41(2):196-205.

33. Gorelick MH, Shaw KN, Murphy KO. Validity and reliability of clinical signs in the diagnosis of dehydration in children. Pediatrics 1997;99(5):E6.

34. Duggan C, Refat M, Hashem M, Wolff M, Fayad I, Santosham M. How valid are clinical signs of dehydration in infants? J Pediatr Gastroenterol Nutr 1996;22(1):56-61.

35. Friedman JN, Goldman RD, Srivastava R, Parkin PC. Development of a clinical dehydration scale for use in children between 1 and 36 months of age. J Pediatr 2004 August; 145(2): 201-7.

36. Shapiro NI, Kociszewski C, Harrison T, Chang Y, Wedel SK, Thomas SH. Isolated prehospital hypotension after trau- matic injuries: a predictor of mortality? J Emerg Med 2003 August;25(2):175-9.

37. MacLeod J, Lynn M, McKenney MG, Jeroukhimov I, Cohn SM. Predictors of mortality in trauma patients. Am Surg 2004 September;70(9):805-10.

38. Rivers EP, McIntyre L, Morro DC, Rivers KK. Early and innovative interventions for severe sepsis and septic shock: taking advantage of a window of opportunity. Can Med Assoc J 2005 October;173(9):1054-65.

39. Wilkins B, Goonasekra CDA, Dillon MJ. Water, electrolyte and acid-base disorders and acute renal failure. In: Macnab A, Macrae D, Henning R, editors. Care of the critically ill child. Edinburgh: Churchill Livingstone; 1999.

40. Finfer S, Bellomo R, Boyce N, French J, Myburgh J, Norton R, et al. A comparison of albumin and saline for fluid resuscitation in the intensive care unit [see comment]. N Eng J Med 2004 May;350(22):2247-56.

41. Perel P, Roberts I. Colloids versus crystalloids for fluid rescuscitation in critically ill patients. Cochrane Database Syst Rev 2007; (Issue 4):Art. no.: CD000567.

42. Hartling L, Bellemare S, Wiebe N, Russell K, Klassen TP, Craig $W$. Oral versus intravenous rehydration for treating dehydration due to gastroenteritis in children. Cochrane Database Syst Rev 2006;3:CD004390.

43. Fonseca BK, Holdgate A, Craig JC. Enteral vs intravenous rehydration therapy for children with gastroenteritis: a metaanalysis of randomized controlled trials. Arch Pediatr Adolesc Med 2004;158(5):483-90.

44. Hahn S, Kim S, Garner P. Reduced osmolarity oral rehydration solution for treating dehydration caused by acute diarrhoea in children. Cochrane Database Syst Rev 2002; doi:10.1002/14651858.CD002847 (Issue 1):Art. no.:CD002847.

45. Gastanaduy AS, Begue RE. Acute gastroenteritis. Clin Pediatr 1999;38(1):1-12.

46. Royal Children's Hospital. Clinical practice guidelinediarrhoea and vomiting; 2004. Available from: http://www. rch.org.au/clinicalguide/cpg.cfm?doc_id=5192.

47. Santucci KA, Anderson AC, Lewander WJ, Linakis JG. Frozen oral hydration as an alternative to conventional enteral fluids. Arch Pediatr Adolesc Med 1998 February;152(2):142-6.

48. Ducharme J, Matheson K. What is the best topical anesthetic for nasogastric insertion? A comparison of lidocaine gel, lidocaine spray, and atomized cocaine. J Emerg Nurs 2003;29(5):427-30.

49. Wolfe TR, Fosnocht DE, Linscott MS. Atomized lidocaine as topical anesthesia for nasogastric tube placement: a randomized, double-blind, placebo-controlled trial. Ann Emerg Med 2000;35(5):421-5.

50. Mathur A, Duke T, Kukuruzovic R, South M. Hypotonic vs isotonic saline solutions for intravenous fluid management of acute infections. Cochrane Database Syst Rev 2004;(2):CD004169.

51. Duke T, Molyneux EM. Intravenous fluids for seriously ill children: time to reconsider. Lancet 2003 October;362(9392):1320-3. 